\title{
The crocodile caves of Ankarana, Madagascar
}

\author{
Jane M. Wilson
}

In 1981 the FFPS helped fund the Southampton University Expedition to the Ankarana Caves in northern Madagascar. This was the first attempt at any systematic biological work there. Within the longest cave, la Grotte d'Andrafiabé, a striking variety of fauna was found, including several arthropod species that were new to science. This preliminary report, by one of the expedition's members, describes some of the findings. A new 10-man team returned to Ankarana in August 1986 to extend the work.

A team of six people from Southampton University was fortunate in being granted permission to work in Madagascar in 1981. We were all biologists with a keen interest in conservation, but we quickly realized the conflicts between conservation and development. During long, uncomfortable days spent travelling the $1600-\mathrm{km}$ length of the island on crowded local buses, we soon came to appreciate the desperate economic conditions of this beautiful and friendly country. We spent August adding to census data on the two diurnal lemurs at Berenty Reserve in the south (see Howarth et al., 1987) and then travelled to the tropical north to look at cave fauna at Ankarana. Both above and below ground Ankarana proved to have much to interest ecologists and even palaeontologists. This paper concentrates on the fauna living in and around one cave system, but a larger team returned to the area in August 1986 to attempt a more comprehensive study of this remote and little-known nature reserve.

Madagascar's cave-adapted animals are, like the surface dwellers, often bizarre and difficult to classify. For example, one of the two known endemic species of blind troglobitic southern Malagasy fish lacks a lateral line or any other obvious sensory apparatus, and yet it is particularly adept at avoiding capture (Decary and Arnoult, 1981). There is substantial literature on Malagasy cave fauna but most papers are mere Crocodile caves of Madagascar taxonomic descriptions or species' lists (Decary and Keiner, 1970; Paulian, 1961; Remillet, 1973). The biology of Madagascar's cavedwelling animals has received little attention so far, and work in this field is likely to be rewarded by the discovery of new 'missing link' species with fascinating ecology.

The middle Jurassic limestones of Ankarana contain the longest cave systems in Madagascar, and it was these that attracted our attention. Ankarana, confusingly also called Ankara (Réserve Spéciale d'Ankara), is an unwardened 18,200 -hectare reserve, which was set up in 1956. It is in the extreme north of the island at about $13 \mathrm{~S} 49 \mathrm{E}$ and lies about $100 \mathrm{~km}$ south of Antsiranana (Diégo-Suarez).

Over the last 20 years searches for caves at Ankarana have revealed $93 \mathrm{~km}$ of passages (Peyre, 1982, 1984) and there are still more to be found (Radofilao, pers. comm.). The Massif covers an area $28 \mathrm{~km}$ by $8 \mathrm{~km}$ and it is only a little over $200 \mathrm{~m}$ higher than the surrounding plain, but even in the dry season it contains substantial subterranean rivers and provides humid, alkaline refuges from the desiccating conditions of the surrounding scrub. Nile crocodiles Crocodylus niloticus benefit from this water source and hide in the caves from hunters, seeming able to thrive in the deepest sections of the caves, even in absolute darkness. At present 


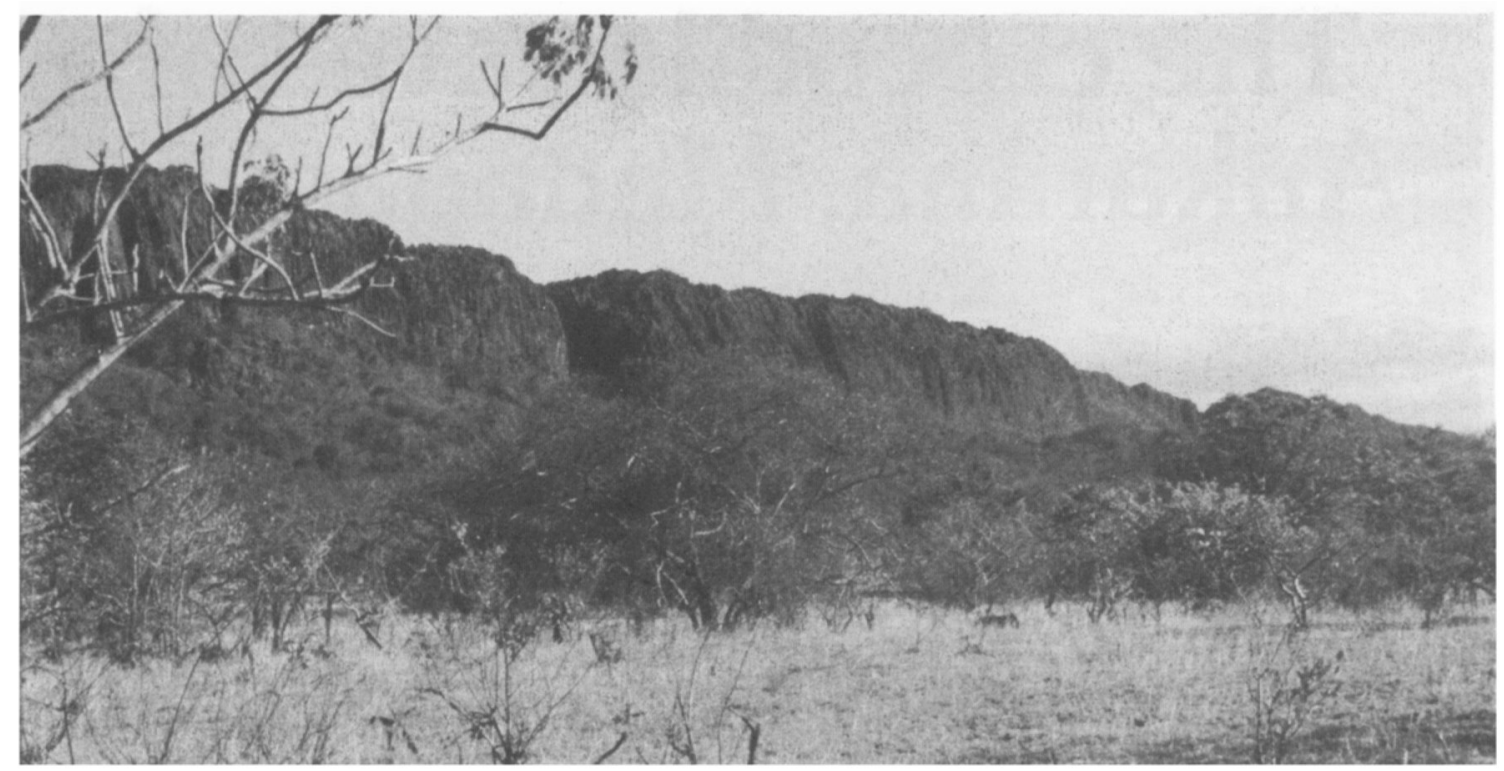

The north-west facing cliffs of the Ankarana Massif (Jane Wilson).

no one knows how much time the crocodiles spend in the dark zone, nor what they feed on or how many live in the area. The Nile crocodile is threatened in Madagascar, and Ankarana is one rare refuge for the species.

The longest known cave system in the Massif (and also on Madagascar), la Grotte d'Andrafiabé, has over $11 \mathrm{~km}$ of 'dry' passage, much of which is 50 $\mathrm{m}$ in diameter. It has many contrasting habitat types, from blue underground lakes to desiccated guano beds; some passages open into dramatic and luxuriant gorges and sunken isolated forests.

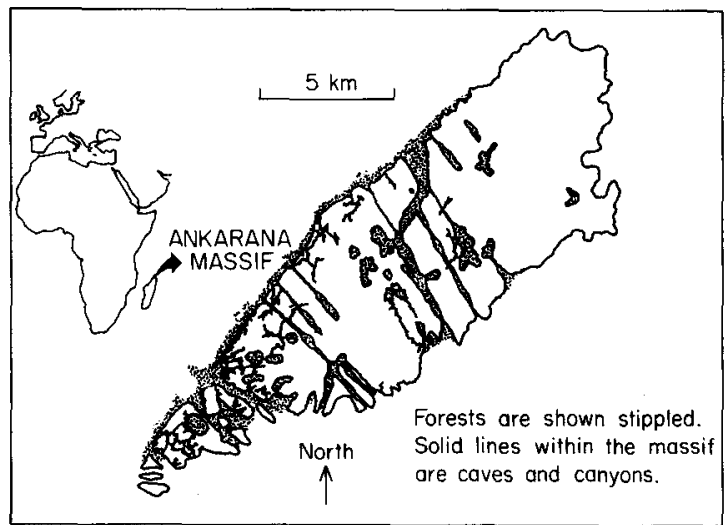

In the blind-ending passages, where the air is still and the humidity approaches 100 per cent, several hundred large leaf-nosed bats Hipposideros commersoni roost. Their faeces and carcasses provide abundant food for invertebrates on the cave floor. Fruit flies and two troglobitic (cave-adapted) Paronelloid springtails Troglopedetes madagascarensis (Wilson, 1982; and one yet to be described) browse on the guano with their predators: mites, troglobitic Psechrid spiders and black troglophilic (non caveadapted cave dwellers) ants Pheidole megacephala. Springtails moult throughout their lives, but since they continue to moult only when well fed, frequency of moulting could be used as an indirect index of the availability of food. The abundance of springtail exuvae wherever there was bat detritis implies that the springtails were gaining adequate nutrition from the bat guano or, more likely, from the fungi growing upon it. The cave-adapted invertebrates appear to have a safe refuge in the constant climatic conditions in which they presently thrive. However, any environmental changes outside the caves (for example, agricultural development and tree-felling) or disturbance that affects the bat population could also threaten the troglobites by cutting off their food supply. It is a rich but very vulnerable community.

Oryx Vol 21 No 1, January 1987 


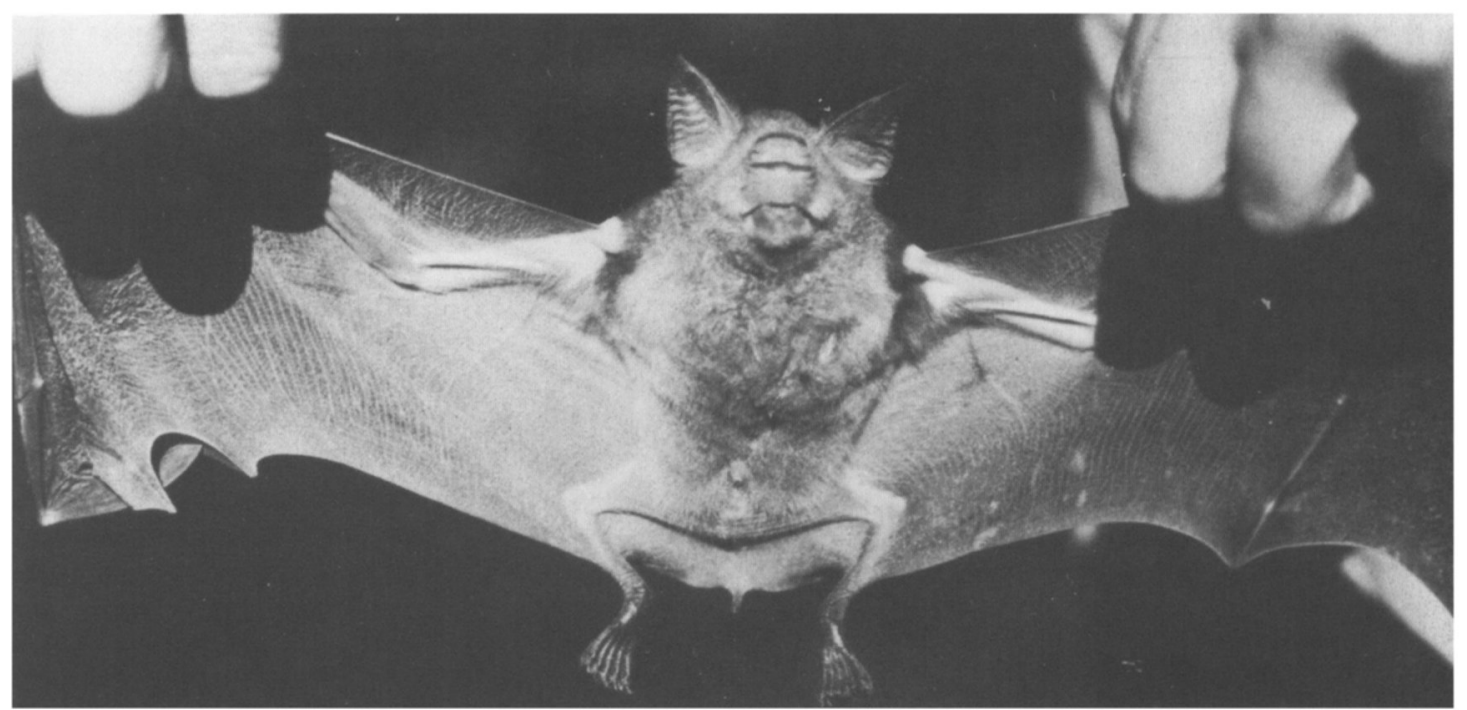

A leaf-nosed bat Hipposideros commersoni whose droppings and remains are food for a variety of cave animals (Jane Wilson).

In the parts of the cave where the substrate is silt rather than guano, white troglophilic woodlice Synarmadillo madagascariensis are to be found, while in the deepest section of the cave system where vast mud banks cover the floor, fungi grows wherever sufficient organic material exists, and troglobitic white diplura (another new species) and springtails graze upon it.

Troglobitic shrimps live in the many small, clear muddy-bottomed lakes throughout this and neighbouring caves, and despite their reduced or absent eyes they are extremely difficult to catch. Nine closely related shrimp species (Gumey, 1984) live in one corner of the Massif, with three con-generic species sharing the same pool in two instances. Shrimps, like springtails, can withstand long periods of starvation, but it is difficult to understand how such closely related species can coexist in cave conditions where food is often at a premium and where competition would be expected to bring about the extinction of all but the most successful species (Culver, 1973).

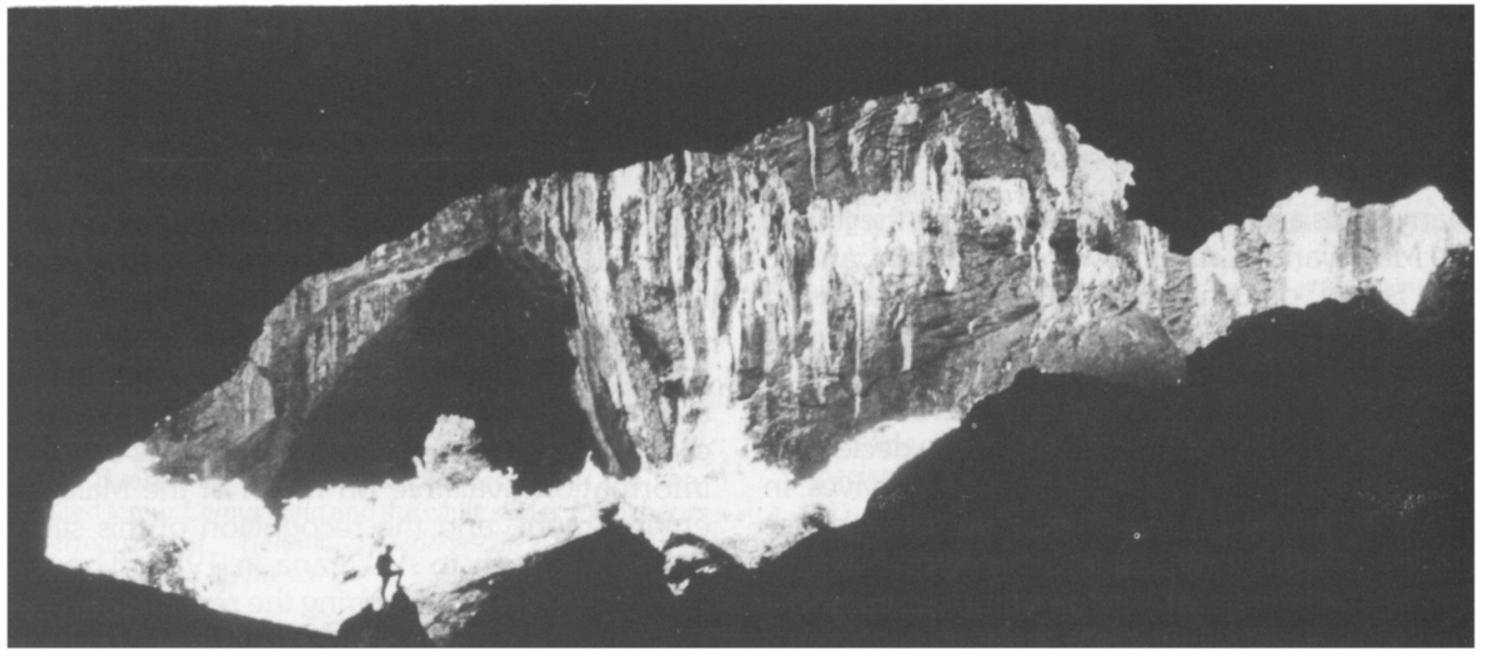

One of the ravines that interrupt the passage of La Grotte d'Andrafiabé ( $M$. Boase). 
In the well-ventilated sections of the cave the humidity falls to around 50 per cent and the humidity-loving, cave-adapted animals are excluded. Here only the drought-resistant troglophiles can survive: booklice, pseudoscorpions and crickets. The $12-\mathrm{m}$ high dry guano beds in this section support huge populations of the American cockroach Periplaneta americana. It is difficult to imagine how even such a ubiquitous species arrived in Ankarana.

Only a small proportion of the invertebrates collected have been identified so far, but eight of these are new species. Speciation appears to be going on at a rapid rate in the area, and there is much more work to be done. Sadly, in many ecological surveys studies are limited to the large obvious species, perhaps because these are most at risk. However, studies of the invertebrates are also of interest, not least because they can prove useful early ecological indicators of subtle environmental changes.

The Massif's cave entrances, cliffs, gorges and isolated forests provide shelter and roosting sites for the Madagascar turtle dove Streptopelia picturata and the Madagascar black swift Apus apus balstoni. The white breasted mesite Mesoenas variegata was also seen here in 1931, but it has not yet been re-sighted. The fruit bats Eidolon helvum roost here too, but local people smoke them out of the caves and knock them down as they leave (Paulian, 1981)-presumably for the pot. This contrasts with behaviour in other parts of Madagascar where bats and butterflies are treated with great respect: they are seen as incarnations of ancestors and it is fady (taboo) to kill them.

Many birds and insects drink at pools at the foot of the Massif and at streams within its gorges, and so this 'island' of lush vegetation seems to act as an oasis for the wildlife of the surrounding dry basalt scrublands. Sheltered by the 200-m north-west facing Ankarana cliffs, and watered by the Massif's natural aquifers, a strip of dry deciduous forest, several hundred metres across, survives. In many places the canopy is closed, with a dense understorey. This forest supports the Malagasy ring-tailed mongoose Galidia elegans and two diurnal lemurs: the crowned lemur Lemur coronatus, which is restricted to a small area of 46 north-east Madagascar, and Sanfords lemur Lemur fulvus sanfordi, one of six subspecies and endangered. Both allowed approach to as close as $5 \mathrm{~m}$ and seemed to be protected from hunting by local fady. Unfortunately this is not the case throughout the ranges of these northern lemurs.

Although the Ankarana lemurs are probably not hunted, they are threatened by environmental changes brought about by the pressures of local agriculture, grazing and tree-felling. Inside one of the sunken isolated forests we found the subfossil skeleton of the endangered broad-nosed gentle-lemur Hapalemur simus. This is hundreds of kilometres from its present known range within the humid forest east of Fianarantsoa, and illustrates how the range of one species has shrunk dramatically over the last 1000 years. It is tempting to speculate that a remnant population might be living still in one of the many unvisited isolated forests of Ankarana. These forests are contained by $200-\mathrm{m}$ high sheer cliffs, and many can only be entered through the caves.

Lemurs were observed travelling over the Massif and had no difficulty leaping across the jagged limestone top nor in scaling the cliffs. They probably supplement food obtained from the poorer, somewhat degraded forest on the outside by browsing on the rich luxuriant flora within. In Madagascar's threatened environment these isolated forests act as important natural nature reserves. The speciation that must be going on within each sunken forest and in the caves that link them will provide plenty of work for any biologists fortunate enough to be able to work in this fascinating region.

Our 10-day reconnaissance to Ankarana enabled us to demonstrate the ecological wealth of the reserve and to produce the most complete ecological study on any Malagasy cave. Our work has also provided most of the information available to date on the Réserve Spéciale d'Ankara. This is a sad reflection on the dearth of information available on much of the Malagasy environment, and the recognition of this stimulated the return to Ankarana in 1986. The new 10-man team is cataloguing the reserve's wildlife, assessing the threats to it and, we hope, initiating some conservation work through local education.

Oryx Vol 21 No 1, January 1987 


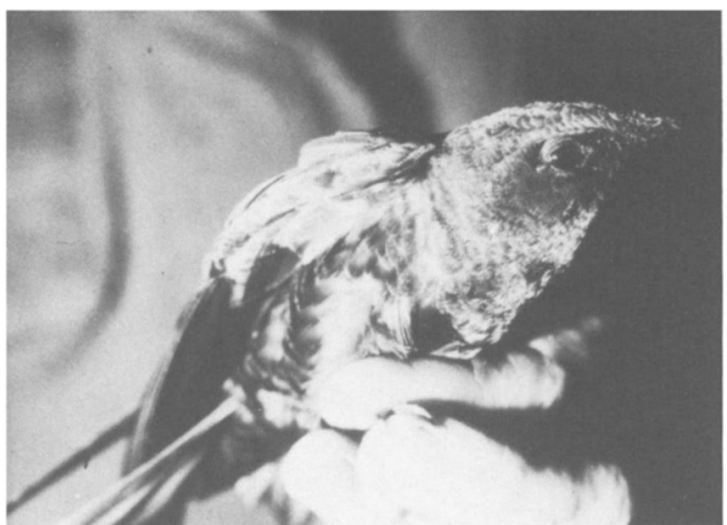

Above: Madagascar black swift, which nests in the entrance of La Grotte d'Andrafiabé (Jane Wilson).

Right: Crowned lemur, which is restricted to a small area of northeast Madagascar and found in the forest at the foot of the Ankarana Massif (A.P. Adamson).

\section{Acknowledgments}

We are indebted to the Government of Madagascar for permission to work in Madagascar, and to the many Malagasy friends who helped us. The other members of the Expedition (André Adamson, Mike Boase, Catherine Howarth, Elizabeth Sparke and Mary Wilson) provided invaluable help. The project was funded by Fauna and Flora Preservation Society, University of Southampton, Churchill Trust (grant to M. E. Wilson), Sports Council, Ghar Parau Foundation, British Ecological Society, French Protestant Church of London, W. A. Cadbury Trust, Westcroft Trust, John Spedan Lewis Fund, Mammal Society, Royal Geographical Society, TwentySeven Foundation and the Gilchrist Trust. The Expedition was approved by the Scientific Exploration Society and the Primate Society of Great Britain.

\section{References}

Culver, D.C. 1973. Competition in spatially heteregenous systems: an analysis of simple cave communities. Ecology, 54, 102-110.

Decary, R. and Amoult, J. 1981. Poissons d'eau douce. In Madagascar, Un Sanctuaire de la Nature (Ed. P. Oberlé), p. 97. Lechevalier, Paris.

Decary, R. and Keiner, A. 1970 Les cavites souterraines de Madagascar. Annales de Speleol. Paris 25, 409-440.

Gurney, A.R. 1984. Freshwater shrimp genera Caridina and Parisa of Madagascar with descriptions of four new species. J. Nat. Hist. 18, 567-590.

Howarth, C.J., Wilson, J.M., Adamson, A.P., Wilson M.E. and Boase M.J. 1987. Population ecology of the ringtailed lemur Lemur catta and the white sifaka, Propithecus verreauxi at Berenty, Madagascar 1981. Folia Primatologica (in press).

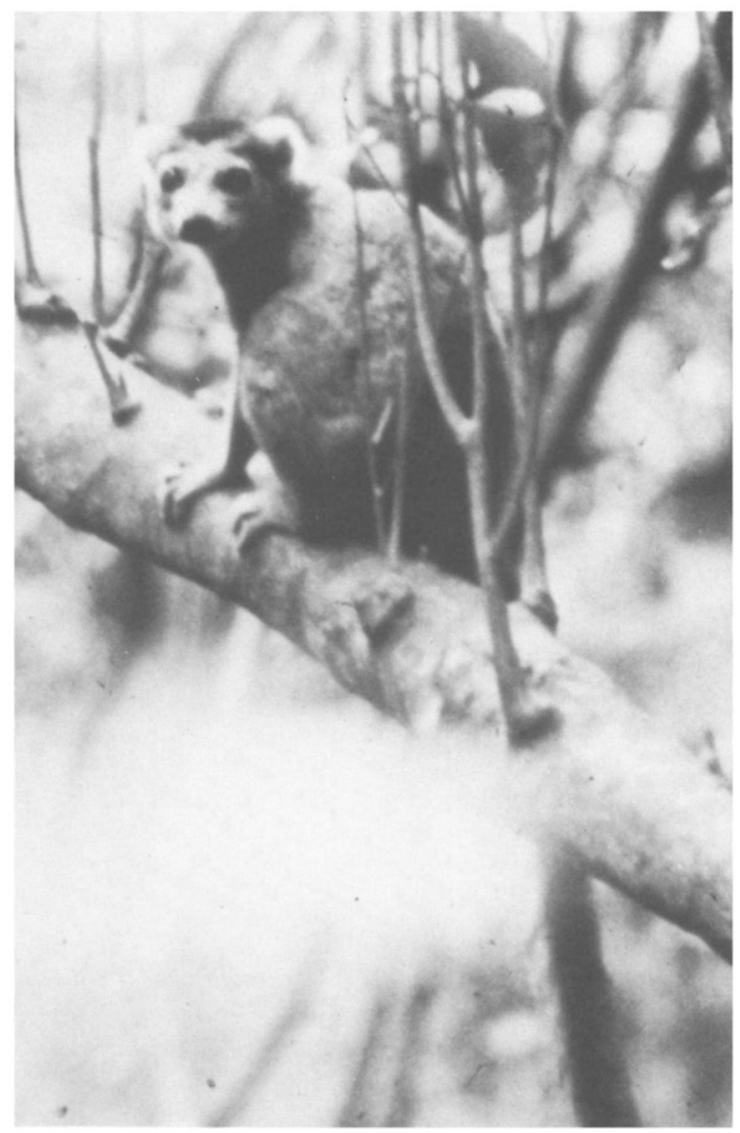

Paulian, R. 1961. La faune cavernicole. In Faune de Madagascar XIII: La Zoogéographie de Madagascar et des Iles Voisines. Publications de l'Institute de Recherche Scientifique, Tsimbazaza, Antananarivo, pp. 94-99.

Paulian, R. 1981. Les Mammifères: vestiges d'un monde disparu. In Madagascar, Un Sanctuaire de la Nature Ed. P. Oberlé), pp. 75-94. Lechevalier, Paris.

Peyre, J.C. 1982. Expedition Speleologique Madagascar 1982. Federation francais de speleogie.

Peyre, J.C. 1984. Speleogie: Special Madagascar 1984. Bull. Club Martel, CAF.

Remillet, M. 1973. Aperçu de la faune souterrainne a Madagascar. In Liure di Clinquantenaire de l'Institut de Speleogie 'Emile Racovitza', pp. 135-159. Inst. Spelol., Bucharest.

Wilson, J.M. 1982. A review of world Troglopedetini, including an identification table and descriptions of new species. Trans. Brit. Cave Res. Assoc. 9, 210-226.

Jane M. Wilson, 69 Thame Road, Warborough, Oxford OX9 $8 \mathrm{EA}, \mathrm{UK}$. 